\title{
東京大学 齋藤聖子・繁栘算男
}

\section{Explanation and estimation of subjective probability by generalized model of Support Theory}

Kiyoko Saito and Kazuo Shigemasu (Department of Life Sciences, Graduate School of Arts and Sciences, The University of Tokyo, Komaba, Meguro-ku, Tokyo 153)

The purpose of this paper is to develop a new model for describing the cognitive process of decision making. Being of a generalization of Tversky and Koehler's Support Theory, the proposed model firstly defines the choice probability among several alternatives in terms of degree of "support." Secondly the model defines the degree of support in terms of objective probability and representativeness. Thirdly, this model specifies the integration process by which one reaches the probability of an event utilizing the already assessed subevents. This model was applied to and tasted by, real experimental data. In the experiment, subjects were asked to evaluate the proportions (a kind of probability) and the degrees of representativeness of two objects. Compared to the estimates derived by a Bayesian approach, the subjective probabilities estimated by the proposed model were shown to be closer to those reported by the subjects.

Key words: Bayesian approach, degree of support, Support Theory, subjective probability.

不確実な状況における意思決定の分析において，主 観確率評価は最も重要な要因の一つである。合理的な 意思決定を行うには，確率法則に従った主観確率評価 が要求される。しかし実際に評価された主観確率は必 ずしも確率法則を満たさず，規範から逸脱する現象は 多くの研究で示されている(Tversky \& Kahneman, 1992). 最近注目すべき理論的発展として Tversky が提案した Support Theory (Tversky \& Koehler, 1994)がある。これは確率評価の対象となる客観事象 は必ずしも主観的な評価の対象として同一の心的過程 を生じないとする考えによって規範からの逸脱現象の 理論的説明を試みたものである。例えば，保険掛金に ついての実験で (Johnson, Hershy, Meszaros, \& Kunreuther, 1993)，すべての場合の看護をカバーする 保険と病気と事故に関する看護をカバーする保険の 2 種類の保険があり，それぞれの保険についての掛けて もよい額を質問したところ, 病気と事故のみカバーす る保険の方が，金額が高いという現象がみられた。こ れは客観確率では特価した事象の方が生起確率が低い にもかかわらず，主観確率が高いことを意味する. Support Theoryではこの現象は“いかなる理由”と いう客観事象にも“病気と事故”という客観事象にも 心的評価プロセスにおいて客観事象とは異なる解釈 （これを Support Theoryでは“仮説”とした）が生 じ，その解釈においては，“病気と事故”の方が“い
かなる理由”より蓋然性が高くなるとし, 評価はそれ を通して行われるため病気と事故のみカバーする保険 の金額が高くなるという現象がおきると説明した.つ まり，同一客観事象に対しても，異なる解釈が存在す れば，異なる主観確率が存在するといえる。このよう に Support Theory は主観確率評価值の規範からの逸 脱の現象記述のみでなく, 逸脱の原因の分析を可能と した.

本研究においてはこの Support Theoryの理論を拡 張し，同一客観事象に対して構成される“仮説”が客 観事象と異なる原因を新たに仮定し，合理的意思決定 を行うための指針を示すモデル—Generalized Support Model（以下GSM と略称する）—を提案し た。本モデルでは, 評価者が自身の主観確率を事前に 予測し，メ夕認知行動によって評価する主観確率を合 理的評価に改善することを可能にする。本論文は GSM を実デー夕に適用し，実験により GSM の有効 性を検証するものである.

\section{Generalized Support Model}

GSM の基本的な仮定を説明する。評価対象の客観 事象は心的過程において，主観事象 (Support Theory で“仮説”と呼んだものに対応する）に写像される. この主観事象はさらに下位レベルにおけるいくつかの 主観事象の複合である。これを主観部分事象と呼ぶ. 
GSM では主観部分事象の選択確率のルールと全体評 価への統合のルールを提案する。

GSM における記述方法は以下のと扔りである。 $T$ を外界の状態を表現する集合であるとする。このとき $T$ は少なくとも 2 要素以上で構成される有限集合で ある。その部分集合を “客観事象”とし， $A^{\prime}$ として 記述する。 $T$ に対応する主観事象の集合を $H$ とし, $A^{\prime}\left(A^{\prime} \subset T\right)$ に対応する, 主観事象を $A(A \subset H)$ とす る。実生活に扔いて客観事象 $A^{\prime}$ は主観的世界に扔い て，個人によって異なるイメージや概念によっておき かえられる可能性があり，それを $V_{1}, V_{2}, V_{3}, \cdots, V_{n}$ と 表す。主観事象 $H$ に扔ける客観事象 $A^{\prime}$ に対応する 主観事象 $A$ は $V_{1}, V_{2}, V_{3}, \cdots, V_{n}$ の和集合である。 $A^{\prime}$ と $A$ の関係はかなり自由性があるが， $A=\phi （ \phi$ は空 事象を表す) なら $A^{\prime}=\phi, A^{\prime} \cap B^{\prime}=\phi$ なら $A \cap B=\phi$ であることは仮定しておく。上記の定義の概略図を Figure 1 に示す.

GSM では, 主観確率 $P$ はベイズ的確率法則に従う 数学的確率ではなく, 評価者が評価する心的確率をさ す。主観事象に対応する客観事象の確率が頻度論的に 定められる場合は, 主観事象に対応する客観確率と

し， $P_{0}$ と記述する。

まず，主観事象の主観確率評価モデルを示す。 $V_{i}$ $\subset A$ かつ $V_{i} \cap V_{j}=\phi(i \neq j)$ のとき, 主観部分事象 $V_{i}$ と $V_{j}$ のうち $V_{i}$ が生起する確率の主観評価值であ る $P\left(V_{i}, V_{j}\right)$ は次のように示される。

$$
P\left(V_{i}, V_{j}\right)=\frac{s\left(V_{i}\right)}{s\left(V_{i}\right)+s\left(V_{j}\right)}
$$

$s\left(V_{i}\right)$ は主観部分事象 $V_{i}$ の支持度である. 支持度 $s\left(V_{i}\right)$ とは，単独にみた $V_{i}$ の生起可能性を反映する 直観的な測度である。式(1)はSupport Theoryにおい てすでに提案されたモデルであるが，GSMでは式 (1) を拡張し, $V_{i}, \cdots, V_{n}$ のうち $V_{i}$ が生起する主観確 率を次のように示されると仮定する。

$V_{i} \subset A$ かつ $V_{i} \cap V_{j}=\phi(i \neq j), i, j=1,2, \cdots, n$ であ るとき

$$
P\left(V_{i}, \bigcup_{j \neq i} V_{j}\right)=\frac{s\left(V_{i}\right)}{s\left(V_{1}\right)+s\left(V_{2}\right)+\cdots+s\left(V_{n}\right)}
$$

とする。

さらにGSMに扔いて支持度という測度の性質を明 確化するために，支持度を次のようにモデル化した。

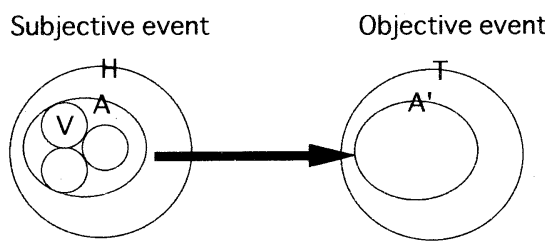

Figure 1. Diagram of GSM.
すなわち支持度 $s\left(V_{i}\right)$ は，

$$
s\left(V_{i}\right)=W_{i} \cdot P_{0}\left(V_{i}\right)+\epsilon
$$

と表され，客観確率 $P_{0}$ を $W_{i}$ によって重みづけした ものである. 客観確率の重みづけ係数 $W_{i}$ は $V_{i}$ の代 表性度 $r\left(V_{i}\right)$ で主に構成されるため, $W_{i}$ は $r\left(V_{i}\right)$ に関係があると仮定する。代表性度とは，評価事象が 典型事象からどの程度離れているかを示す測度である (Tversky \& Kahneman, 1982). 支持度は先に示したよ うに確率評価の基のような存在であるが, 評価事象の 客観確率が評価可能であっても直接主観確率に影響を 及ぼす支持度は代表性によって変形されることを式 (3) は主張している.もちろん一般的には支持度がこ のような客観確率をべースに評価されるとは限らない が, 評価する際に客観確率がデータとして提示されて おり，参考にできる場合などのある種の条件下では， 上記の仮定が有効であると考える。これより式(3)か ら代表性度が高いほど, 客観確率が過大評価され, 低 いほど過小評価されることを意味する。

また $V$ に代表性が全くないと考えられるときは， $V$ の客観確率は無視される.

GSM では, 客観事象に対応する主観事象は評価者 にとって代表性が高い主観部分事象で構成され; それ らのみの評価が行われると仮定する. Robinson \& Hastie (1985), Van Wallendael \& Hastie（1990）は, ある事象に対しての新たな情報が加わると主観確率が 増加する傾向にあるとしている。これは情報の増加に よって主観事象に対する代表性度が高くなり，その結 果支持度が高くなることにつながり, 主観確率の増加 がみられると説明できる。

次に各部分事象の評価を上位集合である主観事象に 統合し，全体評価する評価モデルを示す．決定場面に おいて評価事象は条件つき事象であることが多く,

GSM に扔ける条件つき確率の評価法を示す。このと き所与の条件である客観事象を $C^{\prime}$, それに対応する 主観事象を $C$ と記述する。まず条件つき事象 $A$ が $V_{i}(i=1, \cdots, n)$ に分かれる場合を説明する.

$V_{i} \subset A$ かつ $V_{i} \cap V_{j}=\phi(i \neq j), i, j=1,2, \cdots, n$ であ るとき，規範ルールに従うと

$$
P\left(A^{\prime} \mid C^{\prime}\right)=\sum_{i=1}^{n} P\left(V_{i}^{\prime} \mid C^{\prime}\right)
$$

である。

このように結合過程が主観事象 $A$ において代表性 によって影響されることを仮定し GSM は

$$
P(A \mid C)=\sum_{i=1}^{n} P\left(V_{i} \mid C\right) r\left(V_{i}\right)
$$

である。

次に条件となる事象 $C$ が $V_{j}(j=1, \cdots, m)$ に分か れる場合を示す。

$V_{j} \subset C$ かつ $V_{j} \cap V_{k}=\phi(j \neq k), j, k=1,2, \cdots, m$ で あるとき，規範ルールに従うと 


$$
P\left(A^{\prime} \mid C^{\prime}\right)=\sum_{j=1}^{m} P\left(A^{\prime} \mid V_{j}^{\prime}\right) P\left(V_{j}^{\prime}\right)
$$

である。

このように結合過程が主観事象 $C$ において代表性 によって影響されることを仮定し GSM は

$$
\begin{aligned}
& P(A \mid C)=\sum_{j=1}^{m} P\left(A \mid V_{j}\right) t\left(V_{j}\right) \\
& \text { ただし } t\left(V_{j}\right) \text { は, } t\left(V_{j}\right)=\frac{r\left(V_{j}\right)}{\sum_{j=1}^{m} r\left(V_{j}\right)}
\end{aligned}
$$

となる。

主観部分事象を主観事象に統合するモデル式(5)， (7) は, 数学的確率の統合法則ではなく代表性度によ る主観的バイアスがかかることを意味している。

\section{実験—GSM の検証——}

本実験では主観確率評価を行う質問紙（データは朝 日ジュニア年鑑，1995 による）を作成し，被験者に 質問紙を実施した。

質問紙においては， $V_{i}$ には対応する $V_{i}^{\prime}$ が存在し， かつその客観確率が存在していることは明らかな場合 である。な技実験 $1,2,3$ は GSM 式(3), (5), (7)の 各々の検証を目的とした。

\section{実験 $1-G S M$ 式 (3)の検証実験}

被験者大学生 87 名. JP群 (47 名), US 群 (40 名）の 2 群に分け，各群異なった内容の質問紙を実施 した。実施日は 1994 年 11 月。

手続き 質問紙を配布し，その回答を求めた。時間 は約 20 分.

質問紙の構成 質問紙はJP群US群にそれぞれ 別々の項目群を用意した。項目の内容は “ $C$ という 国の全輸出額のうち $V_{i}$ という項目が占める割合額” を回答する主観確率評価問題である。つまり条件は “ $C$ ”, 評価事象は “ $V$ ” である。 $C$ は JP群は日本, US 群はアメリカ合衆国である。質問紙における $V_{i}$ は主観事象の部分事象である主観部分事象であり，主 観事象は全輸出額である。 $V_{i}$ は JP 群は 4 項目, US 群は 5 項目で構成される。

-JP群 機械類, 工業製品, 化学製品, 食料品

-US 群 機械類, 工業製品, 化学製品, 食料品, 原 材料

被験者には質問は次のように記されている。

1. 指定した 2 項目比較による比率 $P\left(V_{i}, V_{j}\right)$ の評価

例えば機械類と工業製品を比較し，輸出比率を評価 するよう指示した。

2. 代表性度 $r\left(V_{i} \mid C\right)$ の評価 項目 $V_{i}$ の $C$ の生産項 目における代表性度の測定であり, 項目 $V_{i}$ の $C$ の生 産項目における代表性度の測定であり, 被験者には項 目 $V_{i}$ がいかにもCのものであると思う度合を 1 , 全 くCのものでないと思う度合を 0 として数直線上に
○をつけるよう指示した。数直線は 0.1 間隔で目盛り を示した。

実デー夕適用による推定 支持度の決定ルールであ る式(1), (2)を適用し, 得られたデー夕 $P\left(V_{i}, V_{j}\right)$ か ら支持度 $s\left(V_{i} \mid C\right)$ を推定する. 推定した支持度 $s\left(V_{i}\right.$ $\mid C)$ と, $V_{i}$ に対応する客観確率 $P_{0}\left(V_{i} \mid C\right)$ から $W_{i}$ を 推定し， $W_{i}$ が代表性度 $r\left(V_{i} \mid C\right)$ の影響を受けてい るかどうかを分析する。

結果 推定した $W_{i}$ と $r\left(V_{i} \mid C\right)$ の相関を JP, US 群の 2 群について求め, この結果, JP 群においては, 機械類 $(r=.453)$, 工業製品 $(r=.422)$, 化学製品 $(r$ $=.531)$, 食料品 $(r=.571)$ であった. また US 群に おいても, 機械類 $(r=.458)$, 工業製品 $(r=.406)$, 化学製品 $(r=.445)$, 原材料 $(r=.658)$, 食料品 $(r=$ .658）であった.

以上の結果から $W_{i}$ と $r\left(V_{i} \mid C\right)$ の間には相関があ る程度あると考元, 支持度は評価者のもつ事象に対す る代表性に関係があるとした GSM 式(3) は成立する と考える。

\section{実験 2-GSM 式(5)の検証実験}

被験者 被験者は大学生 166 名. JP 群-分野別項目 群 (47 名), 具体的項目群 (44 名), US 群-分野別項 目群 (40 名), 具体的項目群 (35 名) の 4 群に分け, 各群異なった内容の質問紙を実施した。実施日は 1994 年 11 月.

手続き 質問紙を配布し，回答を求めた。時間は約 20 分.

質問紙の構成 質問紙は JP 群-分野別項目群，具 体的項目群, US 群一分野別項目群, 具体的項目群の それぞれに別々の項目群を用意した。内容は実験 1 に 使用した質問紙と同様の主観確率評価問題である。こ の場合に評価される事象は実験 1 の内容と同様に分類 された項目 $V_{i}$ の比率評価と, 全輸出額において加工 貿易が占める割合を評価する。これは項目 $V_{i}$ が加工 貿易の部分事象であるという関係を前提とした。 $V_{i}$ はJP，US群ともに 3 項目である。

JP群

- 分野別項目群一一機械類, 工業製品, 化学製品

・具体的項目群一一自動車, 産業用ロボット, プラス チック製品

US 群

- 分野別項目群一一機械類, 工業製品, 化学製品

・具体的項目群一一航空機, 産業用ロボット, プラス チック製品

被験者に対する質問は次のように記されている。

1. 指定した 2 項目比較による比率 $P\left(V_{i}, V_{j}\right)$ の評価

例えば機械類と工業製品を比較し, 輸出比率を評価 するよう指示した。

2. 輸出総額における加工貿易の占める割合の主観確 
Table 1

Mean and $S D$ of estimated value and actual value for JP-field item group

\begin{tabular}{cccc}
\hline & $n$ & mean & $S D$ \\
\hline estimated value & 46 & .729 & .134 \\
actual data & 47 & .741 & .181
\end{tabular}

Table 2

Mean and $S D$ of estimated value and actual value for JP-concrete item group

\begin{tabular}{cccc}
\hline & $n$ & mean & $S D$ \\
\hline estimated value & 35 & .703 & .162 \\
actual data & 43 & .784 & .139
\end{tabular}

Table 3

Mean and $S D$ of estimated value and actual value for US-field item group

\begin{tabular}{cccc}
\hline & $n$ & mean & $S D$ \\
\hline estimated value & 36 & .323 & .183 \\
actual data & 39 & .308 & .190
\end{tabular}

Table 4

Mean and $S D$ of estimated value and actual value for US-concrete item group

\begin{tabular}{cccc}
\hline & $n$ & mean & $S D$ \\
\hline estimated value & 34 & .330 & .154 \\
actual data & 35 & .299 & .183
\end{tabular}

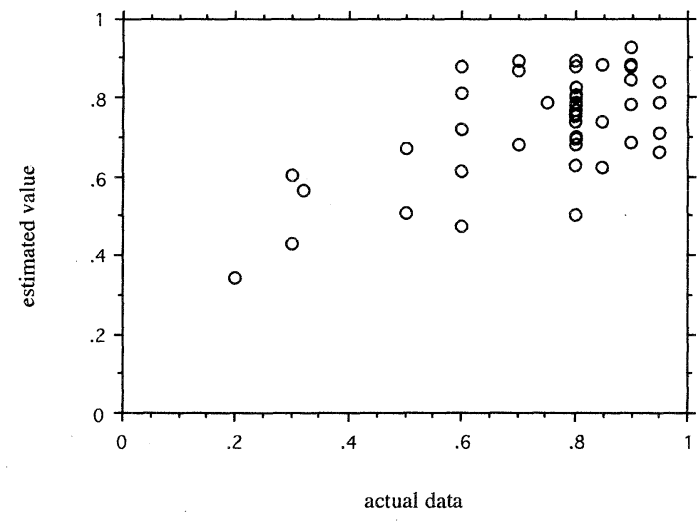

Figure 2. Result of estimated value and actual value for JP-field item group.

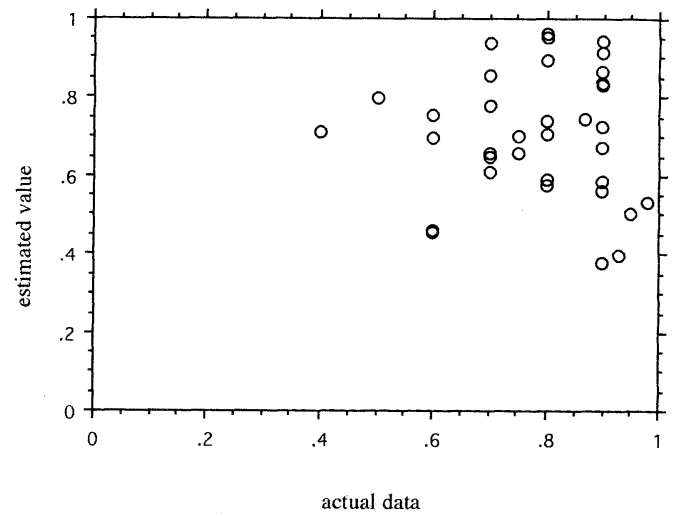

Figure 3. Result of estimated value and actual value for JP-field concrete item group.

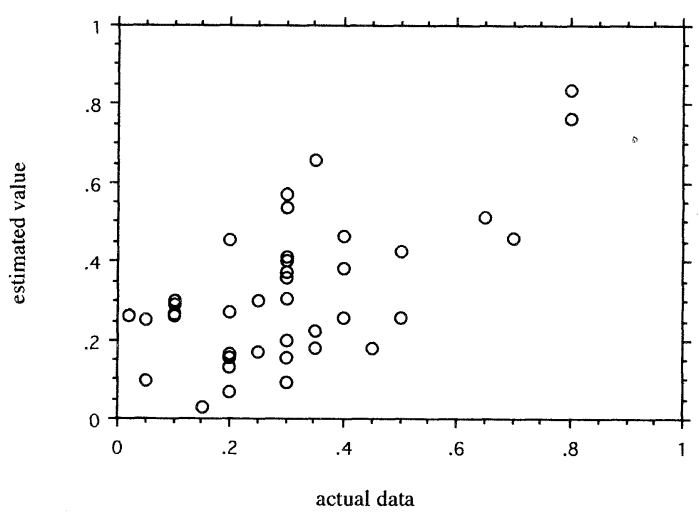

Figure 4. Result of estimated value and actual value for US-field item group.

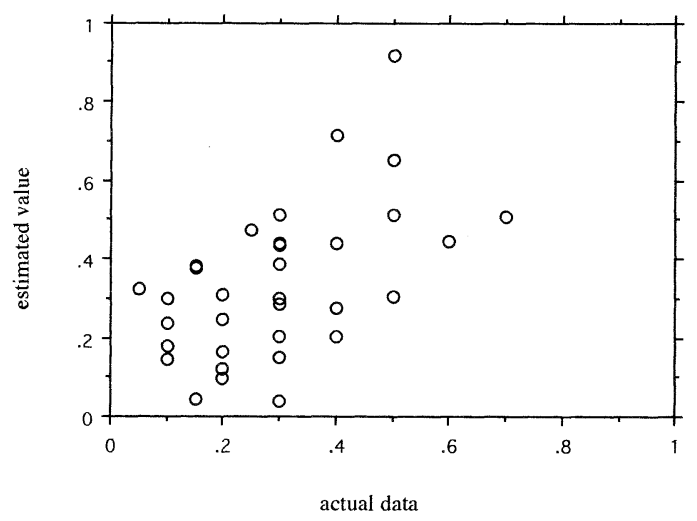

Figure 5. Result of estimated value and actual value for US-concrete item group. 
Table 5

The result of Wilcoxon signed rank test for JP-field item group

\begin{tabular}{crcc}
\hline & $n$ & total & mean \\
\hline rank $<0$ & 10 & 228 & 22.8 \\
rank $>0$ & 36 & 853 & 23.694 \\
$Z=-3.414, p<.01$ & &
\end{tabular}

Table 6

The result of Wilcoxon signed rank test for US-concrete item group

\begin{tabular}{cccc}
\hline & $n$ & total & mean \\
\hline rank $<0$ & 6 & 81 & 13.5 \\
rank $>0$ & 33 & 699 & 21.182 \\
$Z=-4.312, p<.01$ & &
\end{tabular}

Table 7

The result of Wilcoxon signed rank test for US-field item group

\begin{tabular}{cccc}
\hline & $n$ & total & mean \\
\hline $\operatorname{rank}<0$ & 15 & 192 & 12.8 \\
$\operatorname{rank}>0$ & 19 & 403 & 21.211
\end{tabular}

$Z=-1.804, p=.0713$

\section{率評価}

3. 代表性度 $r\left(V_{i} \mid C\right)$ の評価 項目 $V_{i}$ の $C$ の生産項 目における代表性度の測定であり, 被験者にはいかに もCのものであると思う度合を 1 , 全く $C$ のもので ないと思う度合を 0 として数直線上に○をつけるよう 指示した。数直線は 0.1 間隔で目盛りを示した。

実デー夕適用による推定 実データを GSM モデル 式(5)に適用し, 評価された各項目の主観確率值から 加工貿易の主観確率值を推定する。また推定した值と 質問紙で得た加工貿易の主観確率評価值（実測值と呼 ぶ）との近似度を分析する。さらに GSM の妥当性を 検証するために，規範モデルに従った式(4)と実測值 との近似度と比較し, どちらのモデルがより適切なモ デルであるかを検討する。

結果 $P\left(A^{\prime} \mid C^{\prime}\right)$ の実測値と推定值の相関を前述の 4 群 (JP-分野別項目群; JP-具体的項目群；US-分野別 項目群；US-具体的項目群）の各々について求めた. 推定值，実測值は Table 1, 2, 3, 4 に示す。また相関分 析の結果 $\mathrm{JP}$-分野別項目群 $(r=.629)$, 具体的項目群 $(r=.-051)$, US 群一分野別項目群 $(r=.639)$, 具体 的項目群 $(r=.547)$ となり, 4 群中 3 群は推定値は実 測值にある程度近似しているといえる４４群の相関図
Table 8

Mean and $S D$ of estimated value and actual value for conditional group

\begin{tabular}{cccc}
\hline & $n$ & mean & $S D$ \\
\hline estimated value & 50 & .630 & .235 \\
actual data & 50 & .642 & .229
\end{tabular}

Table 9

The result of Wilcoxon signed rank test for conditional group

\begin{tabular}{crcc}
\hline & $n$ & total & mean \\
\hline rank $<0$ & 12 & 126 & 10.5 \\
rank $>0$ & 38 & 1149 & 30.237 \\
$Z=-4.938, p<.01$ & &
\end{tabular}

を Figure 2, 3, 4, 5 に示す.

また，規範モデル式(4)との近似度の比較は，相関 がみられた 3 群について, 規範モデルによる推定值, GSM による推定値の各值と実測值の 2 乗誤差平均を 求め，その差の検定（分布が正規分布ではないため, Wilcoxonの符号順位検定）を行った. その結果，4 群中 3 群の順位平均の差は規範モデルによる推定值の 方が有意に大きかった. 結果は Table 5, 6, 7 に示す.

以上の結果から JP群の具体的項目群以外は GSM の方が規範モデルより実測值に近似しているといえ， 規範モデルよりも日常の主観確率評価をよく表現して いるといえる。

\section{実験 3-GSM 式(7)の検証実験}

被験者 被験者は大学生 50 名. 質問紙を実施した. 実施日は 1994 年 11 月。

手続き 質問紙は 1 種類（条件群とする）を使用し

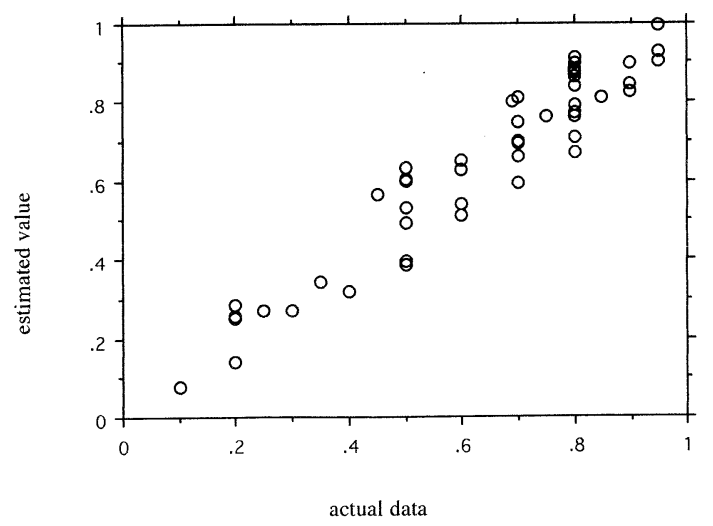

Figure 6. Result of estimated value and actual value for conditional group. 
た。質問紙における主観事象は, “早稲田大学 $V_{j}$ 学 部の $A$ さんが卒業後すぐ大企業に就職する”であり, その主観確率評価を行う内容である。つまり, 条件が 早稲田大学 $C$ 学部であり, 評価事象が大企業への就 職である。質問紙に扔ける主観部分事象は早稲田大学 の各学部であり, 統合後の主観事象は早稲田大学を意 味する. $C$ は 9 学部で構成される.

- 条件群 政治経済学部, 法学部, 第 1 文学部, 第 2 文学部, 教育学部, 商学部, 理工学部, 社会科学部, 人間科学部

被験者に対する質問は次のように記されている.

1. 各学部の早稲田大学における代表性 $r\left(V_{j}\right)$ の評価

早稲田大学そのものであるを 1 とし, 全く早稲田大 学らしくないを 0 として数直線上に○をつけるよう指 示した. 数直線は 0.1 間隔で目盛りを示した。

2. 各学部を条件とした $A$ さんの大企業への就職率の 主観確率 $P\left(A \mid V_{j}\right)$ の評価 $A$ さんを指定した学部と 仮定して回答を指示し, 9 全学部について求める.

早稲田大学の学部の人員構成比率を一覧で示し, 早 稲田大学に所属する $A$ さんの大企業への就職率の主 観確率評価を求めた.

実デー夕適用による推定 実デー夕を GSM モデル 式(7)に適用し， $A$ さんを各学部の所属と仮定した際 の就職の主観確率評価值から早稲田大学に所属する $A$ さんの大企業への就職の主観確率值を推定する. また推定した值と，質問紙で得た早稲田大学に所属す る $A$ さんの大企業への就職の主観確率評価値（実測 值とする）との近似度を分析する。ささら GSM の有 効性を検証するために, 規範モデルに従った式(6)と 実測值との近似度と比較し, どちらのモデルがより適 切なモデルであるかを検討する。

結果 $P\left(A^{\prime} \mid C^{\prime}\right)$ の実測值と推定值の相関を求めた. 推定值, 実測值は Table 8 に示す.

また相関分析の結果 $(r=.952)$, 推定值が実測値に 近似している。相関図を Figure 6 に示す。

また, 規範モデル式(6)との近似度と比較するため に, 規範モデルによる推定值, GSM による推定值の 各值と実測值の 2 乗誤差平均を求め, その差の検定を 行った（分布が正規分布ではないため, Wilcoxonの 符号順位検定)。その結果順位平均の差は規範モデル による推定值の方が有意に大きかった．結果は Table 9・示す.

以上の結果から GSM の方が規範モデルより実測值 に近似しているといえ，規範モデルよりも日常の主観 確率評価をよく表現しているといえる.

\section{考察}

Generalized Support Model は事象の主観確率評価 を行うプロセスに扔いて評価者がもつ評価事象に対す
る代表性尺度が大きく影響を及ぼすことを主張したモ デルである。本研究では実験 1,2,3 から GSM が実際 に評価者の評価プロセスを表しているといえる.

GSM は日常場面における評価者の評価行動を記述 する性質をもつのみでなく, 評価者の評価事象に対す る代表性モデルに応じて, 評価者の事象評価を予測で きるモデルである。これは同時に，事象の代表性度に 過度に影響されないことが, 合理的判断に近くなるこ とも示唆する.

日常における主観確率判断のバイアスが望まれる場 面では, 評価者が GSM を理解し, 代表性によるバイ アスを意識すれば，より良い合理的評価が可能と考え る.

一方では, 代表性度のバイアスがどのプロセスにお いて最も影響を受けるのか, 事象に対する代表性度が すべてのプロセスにおいて同じ尺度によって評価され ているかについては今後さらに分析し, GSM の精緻 化を行うことが, 今後の課題である.

\section{引用文献}

朝日出版社 1995 朝日ジュニア年鑑［統計］。朝日 出版社

Johnson, E. J., Hershy, J., Meszaros, J., \& Kunreuther, H. 1993 Framing, probability distorations and insurance decisions. Journal of Risk and Uncertainty, 7, 35-51.

Robinson, L. B., \& Hastie, R. 1985 Revision of beliefs when a hypothesis is eliminated from consideration. Journal of Experimental Psychology: Human Perception and Performance, 47, 443-456.

繁栘算男 1985 ベイズ統計入門 東京大学出版会

Tversky, A., \& Kahneman, D. 1979 Prospect theory: An analysis of decision under risk. Econometrica, 47, 263-291.

Tversky, A., \& Kahneman, D. 1982 Judgement under uncertainty: Heuristics and biases. Cambridge: Cambridge University Press.

Tversky, A., \& Kahneman, D. 1992 Advances in prospect theory: Cumulative representation of uncertainty. Journal of Risk and Uncertainty, 5, 297323.

Tversky, A., \& Koehler, D. J. 1994 Support theory: A nonextensional representation of subjective probability. Psychological Review, 101, 547-567.

Van Wallendael, L. R., \& Hastie, R. 1990 Tracing the foot-steps of sherlock holmes: Cognitive representations of hypothesis testing. Memory and Cognition, 18, 240-250.

—1996.6.10 受稿, 1997.1.11 受理—— 